\title{
A Study of 1,236 Patients Supporting the Use of Unfractionated Heparin With or Without Glycoprotein IIb/IIIa Inhibitors over Bivalirudin in Primary Percutaneous Coronary Intervention for ST- Segment Elevation Myocardial Infarction: A Changing Trend
}

\section{Isaac Akkad ${ }^{3 *}$, Siddharth Wartak ${ }^{1}$, On Chen ${ }^{1}$, Shiv Raj ${ }^{3}$, Guy Kulbak ${ }^{4}$, Gerald Hollander ${ }^{2}$, Robert Frankel ${ }^{1}$, Jacob Shani ${ }^{1}$ and Bilal Malik ${ }^{1}$}

${ }^{1}$ Department of Interventional Cardiology, Maimonides Medical Center, USA

${ }^{2}$ Department of Cardiology, Maimonides Medical Center, USA

${ }^{3}$ Department of Medicine, Maimonides Medical Center, USA

${ }^{4}$ Department of Cardiac Electrophysiology, Beth Israel Deaconess Medical Center, USA

Submission: February 06, 2017; Published: April 11, 2017

*Corresponding author: Isaac Akkad, Department of Interventional Cardiology, Maimonides Medical Center, Brooklyn, NY 11219, USA, Email: iakkad@maimonidesmed.org

\begin{abstract}
Background
The use of antithrombotic therapy such as heparin and bivalirudin are standard of practice in managing ST-segment elevation myocardial infarction patients undergoing primary percutaneous coronary intervention with a Class I recommendation. Recently the American College of Cardiology published in JACC: Cardiovascular Interventions a study analyzing the trends in anticoagulant use among 513,775 PCIs for STEMI from July 2009 through December 2014 utilizing information available from the National Cardiovascular Data Registry CathPCI Registry. In this study, bivalirudin was associated with a reduction in adverse bleeding events attributed to an increased use of glycoprotein IIb/IIIa inhibitors (GPI) alongside UFH.
\end{abstract}

Objective: To report the efficacy and safety outcomes of UFH with routine use of GPI in primary PCI for STEMI in a high-risk population.

Methods: Single center, retrospective chart review of 1,236 adults undergoing primary PCI. Patients were followed up for 30 days. The primary efficacy outcome was a composite of all-cause mortality, cerebrovascular accident, reinfarction, or stent thrombosis. The primary safety outcome was a composite of access site and non-access site incidence of bleeding.

Results: The rate of MACE was 3(0.2\%) with stent thrombosis, any bleeding event in 30(2.5\%), new myocardial infarction or reinfarction in $7(0.5 \%)$ and mortality rate $(4 \%)$.

Conclusion: In our study UFH with GPI demonstrated a decrease in the rates of stent thrombosis, adverse bleeding events, and new myocardial infarction or reinfarction when compared to RCTs and international registries.

Keywords: Dual antiplatelet therapy; Anticoagulation; Primary percutaneous coronary intervention; ST-segment elevation myocardial infarction; Activated clotting time

\section{Introduction}

For patients with STEMI undergoing primary PCI the following anticoagulation regimens are recommended as Class I: Unfractionated Heparin (UFH) with additional boluses administered to maintain therapeutic activated clotting times (ACT) or bivalirudin with or without previous treatment with UFH. The guidelines also state with Class II level of recommendation that in patients with STEMI undergoing PCI who are at high risk of bleeding, it is reasonable to use bivalirudin monotherapy in preference to the combination of UFH and a GPI.

Bivalirudin use increased substantially in the United States from 2010 till 2014 compared to UFH monotherapy and UFH plus GPI [1]. However, the use of bivalirudin is not a universal practice 
due to the concerns of increased risk of stent thrombosis [2,3]. In 2014, HEAT PPCI study showed UFH to be equally efficacious and safer as compared to bivalirudin [4]. Since HEAT PPCI was published in 2014 bivalirudin usage decreased substantially and UFH monotherapy as well as UFH plus GPI usage increased changing the trend back in favor of UFH in STEMI [1]. More importantly based in our individual center experience the actual bleeding rates with UFH plus GPI are lower than those reported in randomized controlled trials (RCTs) and in line with recent study published in JACC: Cardiovascular Interventions [1]. Our center predominantly uses UFH plus GPI. In this study we aimed to review our single center experience with the cautious use of GPI's in addition to UFH in a high-risk population including patients with high risk angiographic features, advanced heart failure, previous MIs and significant comorbid conditions with a real world experience.

In recent years the use of radial artery access has increased dramatically in STEMI patients undergoing intervention, favorable affecting adverse bleeding events. The use of vascular closure devices has helped achieve rapid closure of the femoral access site. Monitoring ACT and choosing low dose Heparin boluses has improved bleeding outcomes. All these points raise an important question of real indications for bivalirudin; a drug associated with an increased rate of stent thrombosis and limited mortally benefit.

\section{Data Analysis}

Between June 2009 and April 2015 a total of 1,236 patients underwent primary PCI for STEMI in our tertiary care center. Aspirin naive patients were loaded with $324 \mathrm{mg}$ aspirin preprocedure along with a 3000-4000 IU IV bolus of Heparin. During the procedure we continued with IV Heparin boluses while monitoring ACT and $83 \%$ of patients also received GPI. Patients were prescribed clopidogrel (loading dose, 300 or $600 \mathrm{mg}$ ) or Prasugrel $60 \mathrm{mg}$ or Ticagrelor $90 \mathrm{mg}$ after the PCI. Dual antiplatelet therapy was given daily to all patients during their index hospital stay and was then continued indefinitely. Outcomes observed were stent thrombosis, bleeding rates, reinfarction, stroke, and thirty-day mortality. Baseline characteristics of the study group are listed in Table 1. Mean age of our patient population was 66 years and $975(78 \%)$ were males. Comorbidities included $772(62 \%)$ with hypertension, 422(34\%) diabetes, 546(44\%) hyperlipidemia, and 529(42\%) had a smoking history. Available data from 1,182 patients showed that left ventricular ejection fraction was $>55 \%$ in $192(17 \%)$, $45-54 \%$ in $302(25 \%), 35-44 \%$ in $392(33 \%)$, and less than $35 \%$ in $296(25 \%)$ of patients. The rate of MACE was limited to $3(0.2 \%)$ with stent thrombosis, any bleeding event in $30(2.5 \%)$, new myocardial infarction or reinfarction in $7(0.5 \%)$ and a total mortality rate of $(4 \%)$. In the landmark HEAT-PPCI trial, they recruited a near "all-comers" population. The observed adverse event rates more closely matched institutional norms and the results reported by national registries. Their death rate was $4.3 \%$, cerebrovascular accident post PCI of $1.2 \%$, new myocardial infarction or reinfarction of
$0.9 \%$, stent thrombosis $0.9 \%$, and any bleeding event rate of $13.5 \%$ in the Heparin arm of the trial.

Table 1: Demographics of study population.

\begin{tabular}{|c|c|}
\hline Baseline Characteristics & Study Group ( $n=1236)$ \\
\hline Mean Age in (years) & 66.1 \\
\hline Male Sex & $975 / 1236(78 \%)$ \\
\hline Female Sex & $261 / 1236(22 \%)$ \\
\hline Median Body Weight(kg) & 80.7 \\
\hline \multicolumn{2}{|l|}{ Co-morbidities } \\
\hline Hypertension & $772 / 1236(62 \%)$ \\
\hline Diabetes & $422 / 1236(34 \%)$ \\
\hline Hyperlipidemia & $546 / 1236(44 \%)$ \\
\hline Smoking History & $529 / 1236(42 \%)$ \\
\hline Previous $\mathrm{PCI}^{*}$ & $236 / 1236(18 \%)$ \\
\hline Previous CABG* & $41 / 1236(3 \%)$ \\
\hline Average Creatinine (mg/dl) & 1.1 \\
\hline History of Hemodialysis & $10 / 1236(0.8 \%)$ \\
\hline Previous CVA* & $78 / 1236(6 \%)$ \\
\hline Ejection Fraction (EF) & $\begin{array}{r}\text { Data available } \\
929 / 1236(75 \%) \\
\end{array}$ \\
\hline Normal (EF > 55\%) & $192 / 1182(17 \%)$ \\
\hline Mildly Impaired (EF 45-54\%) & $302 / 1182(25 \%)$ \\
\hline Moderately impaired (EF 35-44\%) & $392 / 1182(33 \%)$ \\
\hline Severely Impaired (EF <35\%) & $296 / 1182(25 \%)$ \\
\hline Arterial Access Site & $\begin{array}{r}\text { Data Available } \\
1101 / 1236(90 \%) \\
\end{array}$ \\
\hline Femoral & $1083 / 1101(98 \%)$ \\
\hline Radial & $16 / 1101(2 \%)$ \\
\hline Mean ACT* in catheterization lab & 301.64 seconds \\
\hline Hemoglobin Before PCI* & $\begin{array}{r}\text { Data Available } \\
1202 / 1236(97 \%)\end{array}$ \\
\hline Mean Hemoglobin & $14.09 \mathrm{~g} / \mathrm{dl}$ \\
\hline
\end{tabular}

${ }^{*} \mathrm{PCl}$ : Percutaneous Coronary Intervention; CABG: Coronary Artery Bypass Grafting; CVA: Cerebrovascular Accident; ACT: Activated Clotting Time

The longstanding debate between heparin or bivalirudin in primary percutaneous coronary intervention usually balances the increased risk of stent thrombosis found with bivalirudin versus the increased risk of bleeding with UFH plus GPI. We believe that ACT guided dosing of Heparin, decreased duration of therapy with a glycoprotein IIb/IIIa inhibitor, radial artery access site, and frequent use of a closure devices in femoral access dramatically decrease the bleeding rates while using UFH in patients undergoing PCI.

Also data from the European Society of Cardiology showed that adding a GPI to UFH might be beneficial in patients presenting early with a large myocardial infarction and high thrombus burden [5]. Main culprit lesion treated with PCI, drugs used, type of stent used and Timi flow can be found on Table 2, $3 \& 4$. 
Table 2: Main culprit lesion treated with $\mathrm{PCl}$.

\begin{tabular}{|c|c|}
\hline $\begin{array}{l}\text { Main Culprit Lesion Treated } \\
\text { with Primary PCI }\end{array}$ & $\begin{array}{c}\text { Data Available 1041/1236 } \\
\text { (84\%) }\end{array}$ \\
\hline $1^{\text {st }}$ Diag or Int Branch & 28 \\
\hline $1^{\text {st }} \mathrm{LPL}$ & 12 \\
\hline $1^{\text {st }} \mathrm{Ob} \mathrm{Marg}$ & 35 \\
\hline $1^{\text {st }} \mathrm{RPL}$ & 9 \\
\hline $1^{\text {st }}$ Septal & 1 \\
\hline $2^{\text {nd }}$ Diag & 8 \\
\hline $2^{\text {nd }} O b$ Marg & 28 \\
\hline $3^{\text {rd }}$ Ob Marg & 5 \\
\hline Ac Marg & 1 \\
\hline Artery Graft to LAD & 1 \\
\hline Dist Circ & 31 \\
\hline Dist LAD & 9 \\
\hline Dist RCA & 69 \\
\hline L AV & 1 \\
\hline LMCA & 3 \\
\hline LPDA & 1 \\
\hline Mid LAD & 196 \\
\hline Mid RCA & 132 \\
\hline Prox Circ & 49 \\
\hline Prox LAD & 252 \\
\hline Prox RCA & 153 \\
\hline R PDA & 9 \\
\hline RPLS & 2 \\
\hline Vein graft to LCX & 3 \\
\hline Vein Graft to RCA & 3 \\
\hline
\end{tabular}

Table 3: Drug used, type of Stent used.

\begin{tabular}{|c|c|}
\hline $\begin{array}{c}\text { Therapy with P2Y12 Inhibitor in } \\
\text { Addition to Aspirin after PCI }\end{array}$ & $\begin{array}{c}\text { Data Available } \\
\mathbf{9 2 9 / 1 2 3 6}(\mathbf{7 5 \%})\end{array}$ \\
\hline Clopidogrel & $473 / 929(51 \%)$ \\
\hline Prasugrel & $374 / 929(41 \%)$ \\
\hline Ticagrelor & $82 / 929(8 \%)$ \\
\hline GP2b/3a Inhibitor use at the time of PCI & $1034 / 1236(83 \%)$ \\
\hline
\end{tabular}

\begin{tabular}{|c|c|}
\hline Type of Stents Used & $\begin{array}{c}\text { Data available } \\
\mathbf{9 5 6 / 1 2 3 6} \mathbf{( 7 7 \% )}\end{array}$ \\
\hline Covered stent & 1 \\
\hline Everolimus coated stent (XIence) & 553 \\
\hline Paclitaxel coated stent ( Taxus) & 88 \\
\hline Resolute ZES & 14 \\
\hline Un-Coated Stent & 244 \\
\hline Zotarolimus coated stent ( Endeavor) & 43 \\
\hline No stent Used & 13 \\
\hline
\end{tabular}

$\mathrm{PCl}$ denotes Percutaneous Coronary Intervention, GP Glycoprotein

Table 4: TIMI flow before and after PCI.

\begin{tabular}{|c|c|}
\hline TIMI flow Before PCI & $\begin{array}{c}\text { Data Available 1036/1237 } \\
\text { (84\%) }\end{array}$ \\
\hline 0: No flow/ No perfusion & $647 / 1037(62 \%)$ \\
\hline $\begin{array}{l}\text { 1: Slow penetration without } \\
\text { perfusion }\end{array}$ & $64 / 1037(6 \%)$ \\
\hline $\begin{array}{c}\text { 2: Partial flow } / \text { perfusion }(>1 \\
\text { but }<3 \text { ) }\end{array}$ & $185 / 1037(18 \%)$ \\
\hline $\begin{array}{l}\text { 3: Complete and brisk flow/ } \\
\text { Perfusion }\end{array}$ & $140 / 1037(14 \%)$ \\
\hline TIMI flow achieved after PCI & $\begin{array}{c}\text { Data Available 1013/1236 } \\
\text { (81\%) }\end{array}$ \\
\hline 0: No flow/ No perfusion & $14 / 1013(1.2 \%)$ \\
\hline $\begin{array}{l}\text { 1: Slow penetration without } \\
\text { perfusion }\end{array}$ & $9 / 1013(0.08 \%)$ \\
\hline $\begin{array}{l}\text { 2: Partial flow } / \text { perfusion }(>1 \\
\text { but }<3 \text { ) }\end{array}$ & $21 / 1013(2 \%)$ \\
\hline $\begin{array}{l}\text { 3: Complete and brisk flow/ } \\
\text { Perfusion }\end{array}$ & $969 / 1013(96 \%)$ \\
\hline
\end{tabular}

Our results predominantly using UFH and GPI in STEMI patients undergoing primary PCI shows decreased stent thrombosis, bleeding, and new myocardial infarction or reinfarction rates as compared to both RCTs and international registries (Table 5). Our PRBC transfusion rates of $2 \%$ were comparable to landmark RCTs and international registries. Our death rate of $4 \%$ was lower than in real world registries but higher than RCTs.

Table 5: Comparison of Heparin with GPI study group with other RCTs and International registries.

\begin{tabular}{|c|c|c|c|c|c|c|c|}
\hline & $\begin{array}{c}\text { Heparin with } \\
\text { GPI (Study } \\
\text { Group) } \\
\mathbf{n = 1 2 3 6}\end{array}$ & $\begin{array}{c}\text { Bivaluridin } \\
\text { Arm } \\
\text { (Horizons } \\
\text { AMI) }\end{array}$ & $\begin{array}{c}\text { Bivaluridin } \\
\text { Arm (Heat } \\
\text { PPCI) }\end{array}$ & $\begin{array}{c}\text { Bivaluridin } \\
\text { Arm } \\
\text { (EUROMAX) }\end{array}$ & $\begin{array}{c}\text { Heparin } \\
\text { with GPI } \\
\text { arm (Bright } \\
\text { Trial) }\end{array}$ & $\begin{array}{c}\text { Z-ACS } \\
\text { Registry } \\
\text { n=1787 }\end{array}$ & $\begin{array}{c}\text { FAST-MI 2010 } \\
\text { Registry } \\
\text { n=4169 }\end{array}$ \\
\hline Death Rate & $4 \%$ & $2.1 \%$ & $5.1 \%$ & $2.9 \%$ & $2.1 \%$ & $5.7 \%$ & $4.5 \%$ \\
\hline Stent thrombosis & $0.2 \%$ & $2.5 \%$ & $3.4 \%$ & $1.6 \%$ & $0.7 \%$ & $1.1 \%$ & $(-)$ \\
\hline CVA Post PCI & $0.3 \%$ & $0.5 \%$ & $1.7 \%$ & $0.6 \%$ & $0.8 \%$ & $0.6 \%$ & $0.7 \%$ \\
\hline New MI or Re-infarction & $0.5 \%$ & $2.0 \%$ & $2.7 \%$ & $1.7 \%$ & $0.8 \%$ & $1.6 \%$ & $1 \%$ \\
\hline $\begin{array}{c}\text { Additional unplanned Target } \\
\text { lesion Revascularization }\end{array}$ & $(-)$ & $2.8 \%$ & $2.7 \%$ & $2.7 \%$ & $1.2 \%$ & $(-)$ & $(-)$ \\
\hline Rate of overall bleeding & $2.5 \%$ & $5.9 \%$ & $12.7 \%$ & $7.8 \%$ & $12.3 \%$ & $(-)$ & $(10 \%)$ \\
\hline
\end{tabular}




\section{Methods}

Data was obtained through electronic medical records and notes from health care providers. We utilized proportions, percentages, frequency counts, measures of central tendency, measures of variability, as well as various graphs and tables to report on our descriptive research observations. Since data abstractors who review and code each chart play an important role with respect to data quality, we promoted that coding be performed accurately and consistently, not to compromise the validity of the data to be analyzed. Data abstractors remained blinded to the purpose of the study.

\section{Discussion}

Stent thrombosis and bleeding rates are associated with an increased mortality and clinical practice is based on a balance of this risk. UFH plus GPI use has increased bleeding rates in most trials however we found the therapy to be efficacious as seen in RCTs but more importantly we observe it to be associated with fewer bleeding complications than previously reported. This difference could stem from the lower doses of Heparin used, length and choice of GPI therapy, careful ACT monitoring, and frequent use of closure devices. The benefit of bivalirudin seen in trials is driven by a decreased bleeding rate at the expense of an increased incidence of stent thrombosis [6]. This benefit is likely to decrease with time as intervention techniques and technology advances occur such as the use of vascular closure devices and transradial access. Studies have also shown bivalirudin having no difference in adverse bleeding rates when compared to UFH plus GPI utilizing transradial access [1]. RCTs have shown bivalirudin to have a fivefold increased risk of stent thrombosis $[2,3]$. In the Horizon AMI trial, approximately $65 \%$ of patients received Heparin and analysis showed that randomization to Heparin and a 600mg clopidogrel loading dose were independent predictors of reduced acute and sub-acute stent thrombosis. The increased risk of stent thrombosis in the bivalirudin arm could be explained by its shorter half-life, however, the matrix Trial comparing bivalirudin with unfractionated Heparin in acute coronary syndrome failed to show any added advantage of an extended infusion of bivalirudin. More importantly the mace rates were not lower with bivalirudin, thus nullifying any advantage over heparin [7,3]. In the Euromax trial there was no mortality benefit at 30 days unlike Horizon trial, which showed the benefit but was not powered appropriately [2-4].

Our study shows a significantly lower incidence of stent thrombosis of $0.2 \%$ and overall bleeding rate of $2.5 \%$. These results are very encouraging when compared to bleeding and stent thrombosis rates during the Heat PPCI and Bright trials [812]. We believe that a shorter length of GPI therapy restricted to equal or less than 16 hours with either Abciximab, Tirofiban or Eptifibatide, cautious heparin dosing with ACT monitoring ranging between 250-320 seconds, post-procedure 4-6 hour bed rest and frequent use of a closure devices significantly impacts adverse bleeding events. All these points question the utility of bivalirudin; a drug associated with an increased rate of stent thrombosis and limited mortally benefit. Hence the trend of use for bivalirudin has decreased recently with most centers switching back to UFH with or without a GPI $[1,13$ 15]. We cannot ignore the lesser bleeding rates reported with bivalirudin in Horizon AMI, EUROMAX, MATRIX, and other trials $[2,3,7]$. Perhaps the limited advantage of bivalirudin could be useful in select patients with a higher risk of bleeding. In patients presenting early with high-risk angiographic features and high thrombus burden, UFH plus a GPI was shown to be a safe and effective therapy during primary PCI for high-risk STEMI patients. Seeing our encouraging results we solely cannot switch or recommend routine use of bivalirudin when compared to unfractionated Heparin.

The death rate was reported to be $4 \%$. Compared to the landmark RCTs this number is slightly higher, but we would like to stress that our population was older, had significantly more patients with advanced heart failure, previous MIs, and significant comorbid conditions with a real world experience. Also most of our patients were treated with a GPI that would generally increase bleeding. In spite of these measures our bleeding rates were below expected range as compared to RCTs and international registries.

A limitation of our study is that it is a retrospective chart review and we have used randomized trials and registries as cohort controls. We don't have information on the incidence of thrombocytopenia and bleeding rates at 30 days. However stent thrombosis and bleeding complications are commonly seen within the first 72 hours post procedure and reported in our study. We don't have data on post procedure bed rest, \% of closure device usage versus manual compression to achieve hemostasis, or duration of GPI post procedure. Nevertheless it is routine practice in our institution to have post procedure bed rest for 4-6 hours, and GPI infusion limited to equal or less than 16 hours. The use of closure devices for femoral access is routine in our institution as long as the arterial puncture site is below the inguinal ligament and above the femoral bifurcation.

\section{Conclusion}

In our study UFH with GPI demonstrated a decrease in the rates of stent thrombosis, adverse bleeding events, and new myocardial infarction or reinfarction when compared to most RCTs and international registries. This data is consistent with recent studies and hence the trend of bivalirudin versus UFH with or without GPI has been changing in favor of UFH. We cannot ignore the lesser bleeding rates reported with bivalirudin in Horizon AMI, EUROMAX, MATRIX and other trials. Perhaps the limited advantage of bivalirudin could be used in select patients with a higher risk of bleeding, especially with femoral access. However seeing our encouraging results we solely cannot switch nor recommend routine use of bivalirudin when compared to unfractionated heparin with or without glycoprotein IIb/IIIa inhibitors. 


\section{References}

1. Secemsky EA, Kirtane A, Bangalore S, Jovin IS, Shah RM, et al. (2016) Use and effectiveness of bivalirudin versus unfractionated heparin for percutaneous coronary intervention among patients with ST-segment elevation myocardial infarction in the United States. JACC Cardiovasc Interv 9(23): 2376-2386.

2. Steg PG, Van't Hof A, Hamm CW, Clemmensen P, Lapostolle F, et al. (2013) Bivalirudin started during emergency transport for primary PCI. N Engl J Med 369(23): 2207-2217.

3. Stone GW, Witzenbichler B, Guagliumi G, Peruga JZ, Brodie BR, et al (2008) Bivalirudin during primary PCI in acute myocardial infarction. N Engl J Med 358(21): 2218-2230.

4. Shahzad A, Kemp I, Mars C, Wilson K, Roome C, et al. (2014) Unfractionated heparin versus bivalirudin in primary percutaneous coronary intervention (HEAT-PPCI): an open-label, single centre, randomised controlled trial. Lancet 384(9957): 1849-1858.

5. Savonitto S, De Luca G, Goldstein P, van t'Hof A, Zeymer U, et al. (2017) Antithrombotic therapy before, during and after emergency angioplasty for ST elevation myocardial infarction. Eur Heart J Acute Cardiovasc Care 6(2): 173-190.

6. Cavender MA, Sabatine MS (2014) Bivalirudin versus heparin in patients planned for percutaneous coronary intervention: a metaanalysis of randomised controlled trials. Lancet 384(9943): 599-606.

7. Valgimigli M, Frigoli E, Leonardi S, Rothenbühler M, Gagnor A, et al (2015) Bivalirudin or unfractionated heparin in acute coronary syndromes. N Engl J Med 373(11): 997-1009.

8. Han Y, Guo J, Zheng Y, Zang H, Su X, et al. (2015) Bivalirudinvs heparin with or without tirofiban during primary percutaneous coronary intervention in acute myocardial infarction: the BRIGHT randomized clinical trial. JAMA 313(13): 1336-1346.

9. Ghadri JR, Jaguszewski M, Sacron A (2013) Current outcome of acute coronary syndromes: data from the Zurich-acute coronary syndrome (Z-ACS) registry. Cardiovasc Med 16(4): 115-122.

10. Hanssen M, Cottin Y, Khalife K, Hammer L, Goldstein P, et al. (2012) French Registry on Acute ST-elevation and non ST-elevation Myocardial Infarction 2010. FAST-MI 2010. Heart 98(9): 699-705.

11. Olivari Z, Steffenino G, Savonitto S, Chiarella F, Chinaglia A, et al. (2012) The management of acute myocardial infarction in the cardiological intensive care units in Italy: the 'BLITZ 4 Qualità'campaign for performance measurement and quality improvement. Eur Heart J Acute Cardiovasc Care 1(2): 143-152.

12. Srimahachota S, Boonyaratavej S, Kanjanavanit R, Sritara P, Krittayaphong R, et al. (2012) Thai Registry in Acute Coronary Syndrome (TRACS)-an extension of Thai Acute Coronary Syndrome registry (TACS) group: lower in-hospital but still high mortality at oneyear. J Med Assoc Thai 95(4): 508-518.

13. Rao SC, Chhatriwalla AK, Kennedy KF, Decker CJ, Gialde E, et al. (2013) Pre-procedural estimate of individualized bleeding risk impacts physicians' utilization of bivalirudin during percutaneous coronary intervention. J Am Coll Cardiol 61(18): 1847-1852.

14. Alexander W (2015) Bivalirudin Versus Heparin: A Fight Far From Finished?: Efficacy, Safety, and Cost Remain Battlegrounds for the Treatment Of ST-Segment Elevation Myocardial Infarction. P T 40(3): 209-217.

15. Stables RH (2015) Heparin May Be Hard to Beat: however much you are willing to spend on bivalirudin. JACC Cardiovasc Interv 8(1 Pt B): 221-222.

\section{Your next submission with Juniper Publishers will reach you the below assets}

- Quality Editorial service

- Swift Peer Review

- Reprints availability

- E-prints Service

- Manuscript Podcast for convenient understanding

- Global attainment for your research

- Manuscript accessibility in different formats ( Pdf, E-pub, Full Text, Audio)

- Unceasing customer service

Track the below URL for one-step submission https://juniperpublishers.com/online-submission.php 